\title{
Viral targeting of hematopoietic progenitors and inhibition of DC maturation as a dual strategy for immune subversion
}

\author{
Noemí Sevilla, ${ }^{1,2}$ Dorian B. McGavern, ${ }^{1}$ Chao Teng, ${ }^{1}$ Stefan Kunz, ${ }^{1}$ and Michael B.A. Oldstone1 \\ ${ }^{1}$ The Scripps Research Institute, Division of Virology, Department of Neuropharmacology, La Jolla, California, USA. ²Centro de Biología Molecular Severo Ochoa, \\ Universidad Autónoma de Madrid, Cantoblanco, Madrid, Spain.
}

\begin{abstract}
DCs play a pivotal role in bringing forth innate and adaptive immune responses. Viruses can specifically target DCs, rendering them ineffective in stimulating $T$ cells, which can ultimately lead to immunosuppression. In the present study we have identified several potential mechanisms by which lymphocytic choriomeningitis virus (LCMV) induces immunosuppression in its natural murine host. The immunosuppressive LCMV variant clone 13 (Cl 13) infects DCs and interferes with their maturation and antigen-presenting capacity as evidenced by a significant reduction in the surface expression of MHC class I, MHC class II, CD40, CD80, and CD86 molecules. Additionally, $\mathrm{Cl} 13$ infects hematopoietic progenitor cells both in vivo and in vitro, impairing their development. One mechanism by which hematopoietic progenitors are developmentally impaired is through the $\mathrm{Cl}$ $13-$ induced production of IFN- $\alpha$ and IFN- $\beta$ (IFN- $\alpha / \beta)$. Mice deficient in the receptor for IFN- $\alpha / \beta$ show a normal differentiation of progenitors into DCs despite viral infection. Thus, a virus can evolve a strategy to boost its survival by preventing the maturation of DCs from infected progenitor cells and by reducing the expression of antigen-presenting and costimulatory molecules on developed DCs.
\end{abstract}

\section{Introduction}

DCs, the most potent of the professional APCs, play a central role in the generation of primary $\mathrm{T}$ cell responses and the maintenance of immunity $(1,2)$. Because of their importance in initiating antiviral immune responses, DCs represent an ideal target for viruses seeking to evade the immune system. Several viruses are known to target DCs and impair antiviral T cell responses (3-12). The result can be transient or prolonged suppression of the immune response, often associated with secondary microbial infections or the initiation of a persistent infection, both of which represent serious medical problems. However, the mechanism(s) by which viruses induce dysfunction in DCs is not completely clear. Understanding how viruses interact with DCs is crucial for designing approaches to restore immune function and for treating persistent infections.

To better understand the mechanisms underlying suppression of the immune response following viral infection, we studied lymphocytic choriomeningitis virus (LCMV) infection in its natural murine host. The interaction of this virus with its host has provided a wellcharacterized model of virus-induced immunosuppression. Upon congenital, in utero, or neonatal LCMV infection, persistence of virus results from infection of the thymus, resulting in negative selection with the removal of high-affinity antiviral, potentially effector $\mathrm{T}$ cells (13-16). We (17-21) and others (22-24) described the emergence of unique LCMV variants capable of initiating persistent infections in adult immunocompetent mice. The parental wild-type LCMV, Armstrong 53b (ARM), when inoculated intravenously into adult mice, causes an acute infection characterized by profound expansion of

Nonstandard abbreviations used: Armstrong 53b (ARM); bone marrow cell (BMC); clone 13 (Cl 13); Flt3 ligand (Flt3-L); IFN- $\alpha$ and IFN- $\beta$ (IFN- $\alpha / \beta)$; lymphocytic choriomeningitis virus (LCMV); mean fluorescence intensity (MFI); mixed lymphocyte reaction (MLR); nucleoprotein (NP); recombinant mouse GM-CSF (rmGM-CSF);

relative fluorescence intensity (RFI).

Conflict of interest: The authors have declared that no conflict of interest exists. Citation for this article: J. Clin. Invest. 113:737-745 (2004). doi:10.1172/JCI200420243.
$\mathrm{CD}^{+} \mathrm{T}$ cells. These $\mathrm{T}$ cells are cytotoxic (CTLs), produce perforin and IFN- $\gamma$, and effectively terminate the viral infection within 7 to 10 days (25-27). In contrast, the vast majority of variants (greater than 92\%) also derived from LCMV ARM but isolated from infected lymphoid cells, when similarly inoculated into adult immunocompetent mice, abort CD8 CTL responses, leading to viral persistence (17-19, $21,28)$. One such variant, $\mathrm{Cl} 13$, well characterized molecularly and biologically, is the prototypic immunosuppressive virus of this group $(17,18,21,22,29)$. In contrast to persistent infection initiated early in life, infection of adult mice by $\mathrm{Cl} 13$ and other immunosuppressive variants results in a generalized immunosuppression characterized by ablation of both specific $\mathrm{T}$ cell responses to multiple viruses and antibody responses to many antigens $(28,30)$. Immunosuppression in mice infected with $\mathrm{Cl} 13$ and other immunosuppressive variants of LCMV results from a defect in antigen presentation rather than a lack of $\mathrm{T}$ cell or $\mathrm{B}$ cell function per se $(21,30-34)$. Analysis of splenic replication of immunosuppressive LCMV strains indicated involvement of cells in the marginal zone and white pulp, whereas nonimmunosuppressive viruses localized primarily within the red pulp $(21,28,34)$. Further dissection of the specific cells infected indicated that immunosuppressive viruses preferentially involved two DC subsets: CD11c and DEC-205, with more than $80 \%$ of these splenic DCs infected during the first 20 days after infection (21). In contrast, nonimmunosuppressive viruses infected mainly F4/80-positive macrophages and few $(<10 \%)$ DCs $(21,28)$.

In this report, we trace the events following infection of DCs and their progenitors that result in suppression of the host immune response. Molecular and biological analyses indicate that $\mathrm{LCMV} \mathrm{Cl}$ 13 inhibits the ability of DCs to prime an antiviral immune response by multiple means. First, the immunosuppressive variant $\mathrm{Cl} 13$ prevents the maturation and functional capabilities of DCs, while the nonimmunosuppressive ARM does not. Second, $\mathrm{Cl} 13$ targets and infects the majority of hematopoietic stem cells, rendering them unresponsive to the stimulatory cytokines Flt3 ligand (Flt3-L) in vivo 
and GM-CSF in vitro. Third, as a consequence of $\mathrm{Cl} 13$ virus infection, hematopoietic stem cells show an impaired differentiation and development into CD $8 \alpha^{+}$or CD $8 \alpha^{-}$DCs. In contrast, LCMV ARM is able to infect only $10 \%$ of the progenitors in vivo, and such cells show no impaired differentiation or development into $\mathrm{CD} 8 \alpha^{+}$or $\mathrm{CD} 8 \alpha^{-}$ DCs when treated with Flt3-L or GM-CSF. Finally, we reveal that IFN- $\alpha$ and IFN- $\beta$ (IFN- $\alpha / \beta$ ) play a critical role in impairing the development of hematopoietic progenitors following a $\mathrm{Cl} 13$ infection, as mice deficient in the receptor for this cytokine show a normal differentiation of $\mathrm{CD} 11 \mathrm{c}^{+} \mathrm{CD} 8 \alpha^{+} \mathrm{DCs}$ following Flt3-L stimulation.

\section{Methods}

Viruses and infections. The parental Armstrong 53b (ARM) of LCMV is a triple-plaque-purified clone from Armstrong CA 1371 (35). Clone $13(\mathrm{Cl} \mathrm{13})$ is a triple-plaque-purified variant of this strain derived from spleen cells of an adult BALB/WEHI mouse persistently infected from birth with ARM (18). All virus stocks were grown in baby hamster kidney cells, and the titers were determined by plaque assay on Vero cells as described elsewhere (35). Bone marrow cells (BMCs) were incubated with virus ( 1 hour at $37^{\circ} \mathrm{C}$ ) at an MOI of $10 \mathrm{PFU}$ per cell. Thereafter, cells were washed once with PBS and resuspended in complete RPMI 1640 DC medium (see below) supplemented with $200 \mathrm{U} / \mathrm{ml}$ recombinant mouse GM-CSF (rmGM-CSF) and cultivated with regular changes of medium for 11 days.

Mice and infections. C57BL/6 and 129/SvEv mice maintained in the closed breeding colony of The Scripps Research Institute were used. IFN- $\alpha / \beta \mathrm{R}^{0 / 0}$ mice are described elsewhere (36). Mice were infected at $8-10$ weeks of age by intravenous inoculation of $2 \times 10^{6} \mathrm{PFU}$ of virus as described (21).

Flt3-L treatment of mice. Mice were injected intraperitoneally daily for 10 or 15 consecutive days with $10 \mu \mathrm{g}$ of Flt3-L (Immunex Corp., Seattle, Washington, USA) contained in $200 \mu \mathrm{l}$ of sterile PBS. Control mice received similar inoculations but with $200 \mu \mathrm{l}$ of PBS. The fold expansion of DCs was calculated by dividing the absolute number of each DC subset in Flt3-L-treated mice by the absolute number of cells in PBS-treated mice.

Isolation of splenic DCs. Spleens were obtained from mice infected with $\mathrm{Cl} 13$ or ARM viruses 3, 7, 10, 15, 60, and 120 days after infection. Spleens were incubated with RPMI 1640 complete medium containing collagenase D (1 mg/ml type II; Sigma-Aldrich, St. Louis, Missouri, USA), cut into small fragments, and digested for $20 \mathrm{~min}$ utes at $37^{\circ} \mathrm{C}$. To disrupt T cell-DC complexes, EDTA was added at a concentration of $0.01 \mathrm{M}$ and incubation continued for 5 minutes. Single cells were then obtained by mechanical disruption.

Flow cytometric analysis. Cells were pelleted by centrifugation and resuspended in staining buffer consisting of PBS containing 2\% (vol/vol) FBS and $0.2 \%$ (wt/vol) $\mathrm{NaN}_{3}$ for flow cytometry. To analyze the expression of cell surface molecules, we used monospecific antibodies, fluorochrome dyes, and flow cytometry as published (21). The antibodies used were hamster anti-mouse CD11c-FITC or -PE, rat anti-mouse CD8 $\alpha$-allophycocyanin, rat anti-mouse CD86-PE, rat antimouse CD80-PE, mouse anti-mouse $\mathrm{H}-2 \mathrm{~K}^{\mathrm{b}}$-FITC, and mouse antimouse I-Ab-FITC (all from BD Pharmingen, San Jose, California, USA). After staining, cells were fixed and permeabilized in PBS containing $1 \%$ FBS, $4 \%$ paraformaldehyde, and $0.1 \%$ saponin (wt/vol). An affinity-purified monoclonal antibody to the LCMV nucleoprotein (NP), mAb 113, was conjugated directly to Alexa 488 according to the manufacturer's protocol (Molecular Probes Inc., Eugene, Oregon, USA) and used to detect LCMV NP in the cell cytoplasm. Cells were acquired using a FACSCalibur flow cytometer (Becton, Dickinson, and Co., Franklin Lakes, New Jersey, USA). Dead cells were excluded on the basis of forward and side light scatter. Data were analyzed with FlowJo (Tree Star Inc., San Francisco, California, USA) and CellQuest software (Becton, Dickinson and Co.). The relative fluorescence intensity (RFI) of surface molecules was calculated by dividing the mean fluroescence intensity (MFI) of the indicated cell surface molecules on $\mathrm{CD} 11 \mathrm{c}^{+} \mathrm{CD} 8 \alpha^{+} \mathrm{DCs}$ from $\mathrm{Cl} 13$-infected mice by the MFI on $\mathrm{CD} 11 \mathrm{c}^{+} \mathrm{CD} 8 \alpha^{+} \mathrm{DCs}$ from ARM-infected mice. An RFI of 1.0 indicates that there is no difference between $\mathrm{Cl} 13$ - and ARM-infected mice.

DC culture. BMCs were isolated as described (37). Briefly, BMCs were obtained by flushing femurs and tibias with PBS. The BMCs were resuspended in ammonium chloride for 3 minutes to lyse red blood cells and then mixed with RPMI 1640 (Invitrogen GmbH, Eggenstein, Germany) supplemented with $10 \%$ FCS, penicillin (100 $\mathrm{U} / \mathrm{ml}$, Sigma-Aldrich), L-glutamine (2 mM, Sigma-Aldrich), HEPES (5 mM, Sigma-Aldrich), and 2-mercaptoethanol (50 $\mu \mathrm{M}$, SigmaAldrich). After centrifugation and resuspension at $2 \times 10^{5} \mathrm{cells} / \mathrm{ml}$ in RPMI 1640, cells were seeded at a dose of $2 \times 10^{6}$ per $100-\mathrm{mm}$ dish in $10 \mathrm{ml}$ of culture medium containing $200 \mathrm{U} / \mathrm{ml} \mathrm{rmGM-CSF}$ (PeproTech Inc., Rocky Hill, New Jersey, USA). After every 3 days of culture, half the medium was removed and fresh culture medium supplemented with rmGM-CSF was added to the cultures. To drive BMCs to complete maturation, nonadherent cells were collected at day 10 of incubation and resuspended in $10 \mathrm{ml}$ of culture medium containing $100 \mathrm{U} / \mathrm{ml} \mathrm{rmGM-CSF}$ and LPS (Sigma-Aldrich) at $1 \mu \mathrm{g} / \mathrm{ml}$.

Measurement of T cell stimulation. The ability of splenocytes from uninfected mice and mice infected with ARM or $\mathrm{Cl} 13$ to act as accessory cells for $\mathrm{T}$ cell stimulation in a one-way mixed lymphocyte reaction (MLR) was compared in a $\left[{ }^{3} \mathrm{H}\right]$ thymidine incorporation assay as described (28). Briefly, the responding cells were splenic CD8 ${ }^{+} \mathrm{T}$ cells obtained from BALB/c ByJ $\left(\mathrm{H}-2^{\mathrm{d}}\right)$ mice and purified using a StemSep enrichment cocktail for murine $\mathrm{CD}^{+} \mathrm{T}$ cells (StemCell Technologies Inc., Vancouver, British Columbia, Canada) according to the instructions of the manufacturer. Accessory cells were isolated from the spleens of uninfected C57BL/6 $\left(\mathrm{H}-2^{\mathrm{b}}\right)$ and $\mathrm{C} 57 \mathrm{BL} / 6$ mice infected intravenously with $2 \times 10^{6} \mathrm{PFU}$ of ARM or $\mathrm{Cl} 13$. Splenic cells were placed in suspension and irradiated with $20 \mathrm{~Gy} \gamma$ radiation, after which $5 \times 10^{5}$ cells were mixed with $1 \times 10^{5}$ responder cells in a total volume of $200 \mu$ l. The cells were then incubated at $37^{\circ} \mathrm{C}$ for 5 days. During the final 18 hours of culture, cells were pulsed with $1 \mu \mathrm{Ci}$ of $\left[{ }^{3} \mathrm{H}\right]$ thymidine added to each well and then harvested. The amount of radioactivity incorporated was determined by using a liquid scintillation $\beta$ counter (Beckman Instruments Inc., Fullerton, California, USA). Results shown are the mean $\left[{ }^{3} \mathrm{H}\right]$ thymidine incorporation of triplicate wells.

Immunohistochemistry and confocal microscopy. For immunohistochemical studies, cells were added to polylysine-coated chamber slides (Nalge Nunc International, Naperville, Illinois, USA) and fixed with $4 \%$ paraformaldehyde for 10 minutes, permeabilized with $0.1 \%$ Triton X-100 in PBS for 10 minutes, and blocked with avidin/biotin blocking solution (Vector Laboratories Inc., Burlingame, California, USA). Hamster anti-CD11c (1:100; Serotec Ltd., Raleigh, North Carolina, USA), biotinylated anti-mouse I-Ab (1:20; BD Pharmingen), and guinea pig anti-LCMV $(1: 1,000)$ were incubated at room temperature for 1 hour. As secondary antibodies, anti-hamster IgG conjugated to rhodamine-X, anti-guinea pig IgG conjugated to $\mathrm{Cy} 2$, and streptavidin conjugated to Cy5 were used at a 1:100 dilution. Stained cells were visualized using a Bio-Rad MRC-1024 confocal microscope fitted with a krypton/argon mixed gas laser (excitation at $488 \mathrm{~nm}, 568 \mathrm{~nm}$, and $647 \mathrm{~nm}$ ) and $\times 63$ oil objective (Bio-Rad Laboratories Inc., Hercules, California, USA). 
A

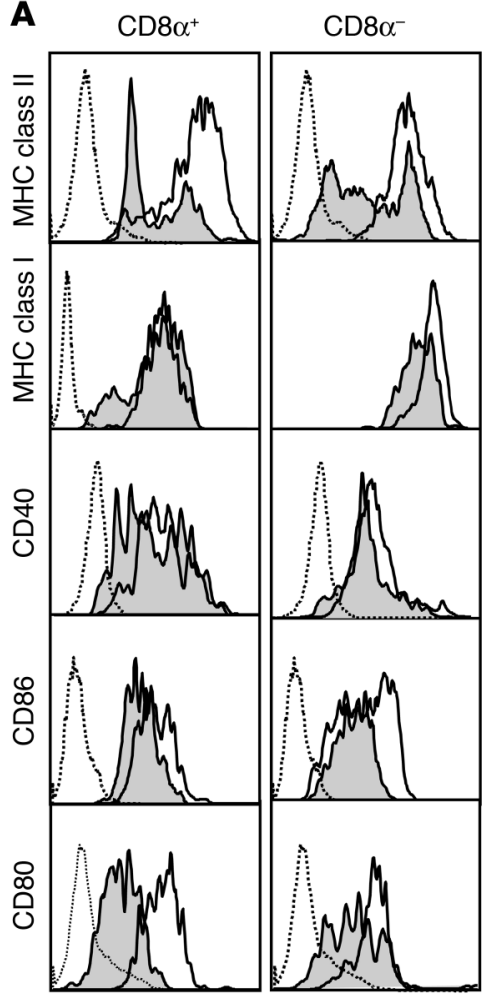

B
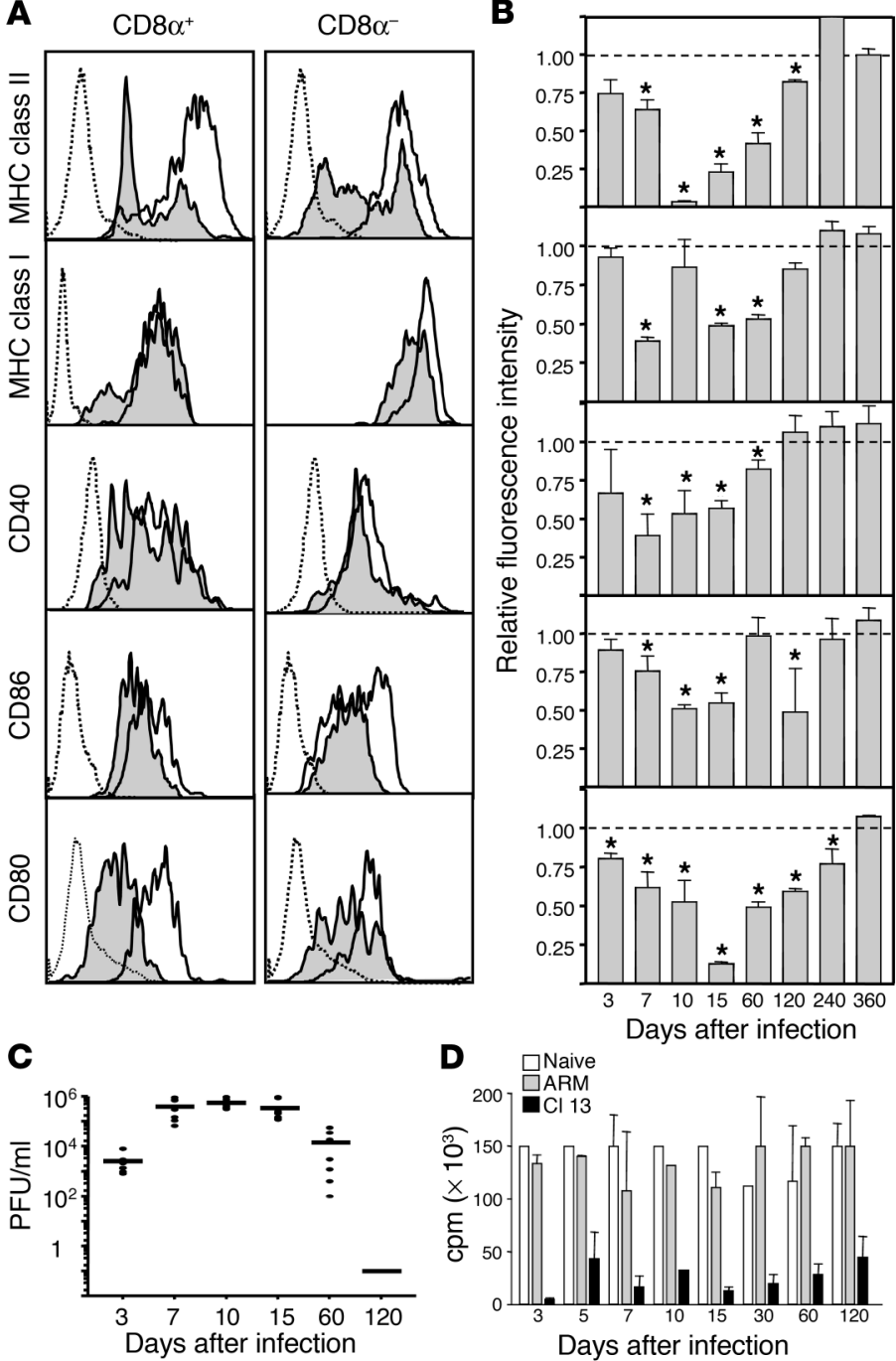

Figure 1

LCMV Cl 13 infection reduces the expression of cell surface molecules on splenic DCs. Labeling with anti-CD11c and -CD8 $\alpha$ antibodies was used to distinguish between $C D 11 \mathrm{C}^{+} \mathrm{CD} 8 \alpha^{+}$and CD $11 c^{+} C D 8 \alpha^{-}$DCs. (A) Histograms show one of four representative experiments analyzing the expression of cell surface molecules on CD $11 \mathrm{c}^{+} \mathrm{CD} 8 \alpha^{+}$and $\mathrm{CD} 11 \mathrm{C}^{+} \mathrm{CD} 8 \alpha^{-}$spleen DCs from $\mathrm{Cl} 13-$ or ARMinfected mice at day 15 after infection. Dotted histograms indicate background staining with isotype control antibodies, white histograms represent ARM-infected mice, and shaded histograms represent $\mathrm{Cl}$ 13-infected mice. (B) The RFI of surface molecules expressed on $\mathrm{CD} 11 \mathrm{c}^{+} \mathrm{CD} 8 \alpha^{+}$splenic DCs from day 3 to day 360 after infection is displayed. Each bar represents the RFI of a given surface molecule on $\mathrm{CD} 11 \mathrm{c}^{+} \mathrm{CD} 8 \alpha^{+}$spleen DCs. The RFI was calculated as indicated in Methods. Data are presented as mean \pm SD. Asterisks denote a statistically significant reduction in $\mathrm{Cl}$ 13-infected mice compared with ARM-infected mice (Student $t$ test, $P<0.05$ ). (C) Viral load in serum of 5-8 Cl 13-infected mice analyzed from day 3 to day 120 after infection as determined by plaque assay. Each filled circle represents an individual mouse. The line at each timepoint represents the mean of all mice in each group. (D) The allostimulatory capacity of DCs from the spleens of either uninfected (white bars), ARM-infected (gray bars), or $\mathrm{Cl}$ 13-infected (black bars) mice is indicated at different timepoints after infection. DCs from infected or uninfected C57BL/6 $\left(\mathrm{H}-2^{\mathrm{b}}\right)$ mice were irradiated and used as stimulator cells for allogeneic $T$ cells from BALB/c $\left(\mathrm{H}-2^{\mathrm{d}}\right)$ mice at a T cell/DC ratio of 5:1 in the MLR. Proliferation was measured in $\mathrm{cpm}$ (average $\mathrm{cpm} \pm \mathrm{SD}$ ) after $\left[{ }^{3} \mathrm{H}\right]$ thymidine incorporation. Each bar represents the average of at least four mice.
Statistical analyses. Data handling, analysis, and graphic representation was performed using Prism 2.01 (GraphPad Software Inc., San Diego, California, USA). Statistical differences were determined using a Student $t$ test or a one-way ANOVA $(P<0.05)$.

\section{Results}

LCMV infection of DCs in vivo markedly inbibits the expression of antigenpresenting and costimulatory molecules. We demonstrated previously that LCMV Cl 13, but not ARM, infects the majority of CD $11 c^{+}$DCs residing in the spleen (21). To expand upon this observation and define the impact that $\mathrm{Cl} 13$ has on the DC population, in the present study we evaluated the expression of the MHC and costimulatory molecules (which are essential to DC function) following infection. Specifically, we measured MHC class I and II, CD40, CD86, and CD80 molecules on CD11 $\mathrm{c}^{+} \mathrm{DCs}$ at various timepoints following infection with LCMV Cl 13 or LCMV ARM. Figure 1A depicts the surface expression of these molecules on lymphoid (CD11 $\left.\mathrm{c}^{+} \mathrm{CD} 8 \alpha^{+}\right)$ and myeloid (CD11 $\left.\mathrm{c}^{+} \mathrm{CD} 8 \alpha^{-}\right) \mathrm{DC}$ subsets at day 15 after infection. When compared with DCs from ARM-infected mice, DCs from Cl 13 -infected mice showed a statistically significant reduction in MHC class I, class II, CD40, CD86, and CD80 molecules on CD8 $\alpha^{+}$ DCs $(P<0.05)$ (Figure 1, A and B). Similarly, CD $8 \alpha^{-}$DCs had a sig- nificant reduction of these molecules (Figure 1A). This diminution in expression cannot be explained by the physical deletion of DCs from $\mathrm{Cl} 13$-infected mice, as the absolute number of DCs was never reduced by more than $50 \%$ at any timepoint analyzed (data not shown). Figure 1B summarizes these molecules on CD $8 \alpha^{+} \mathrm{DCs}$ at timepoints ranging from 3 to 360 days after infection. The maximum reduction of $\mathrm{MHC}$ and costimulatory molecules occurred between days 7 and 15 after infection with the immunosuppressive $\mathrm{Cl} 13$ variant. At the peak of the $\mathrm{Cl} 13$ infection, expression of $\mathrm{MHC}$ class II and CD80 molecules was decreased to near-undetectable levels relative to DCs from ARM-infected mice. By day 120 after infection, when $\mathrm{Cl} 13$-infected mice have cleared the infection, the expression of CD40 and MHC class I molecules recovered completely, whereas a significant reduction remained for MHC class II, CD86, and CD80 molecules $(P<0.05)$. However, by day 360 after infection, the expression of all molecules recovered completely. The same significant pattern of changes, although less pronounced, was observed for $C D 8 \alpha^{-}$DCs (data not shown).

Since the recovery of MHC and costimulatory molecules could have resulted from clearance of LCMV Cl 13, the viral load in sera was quantified by plaque assay at each timepoint displayed (Figure 1C). As expected, ARM-infected mice cleared the viral infection by 

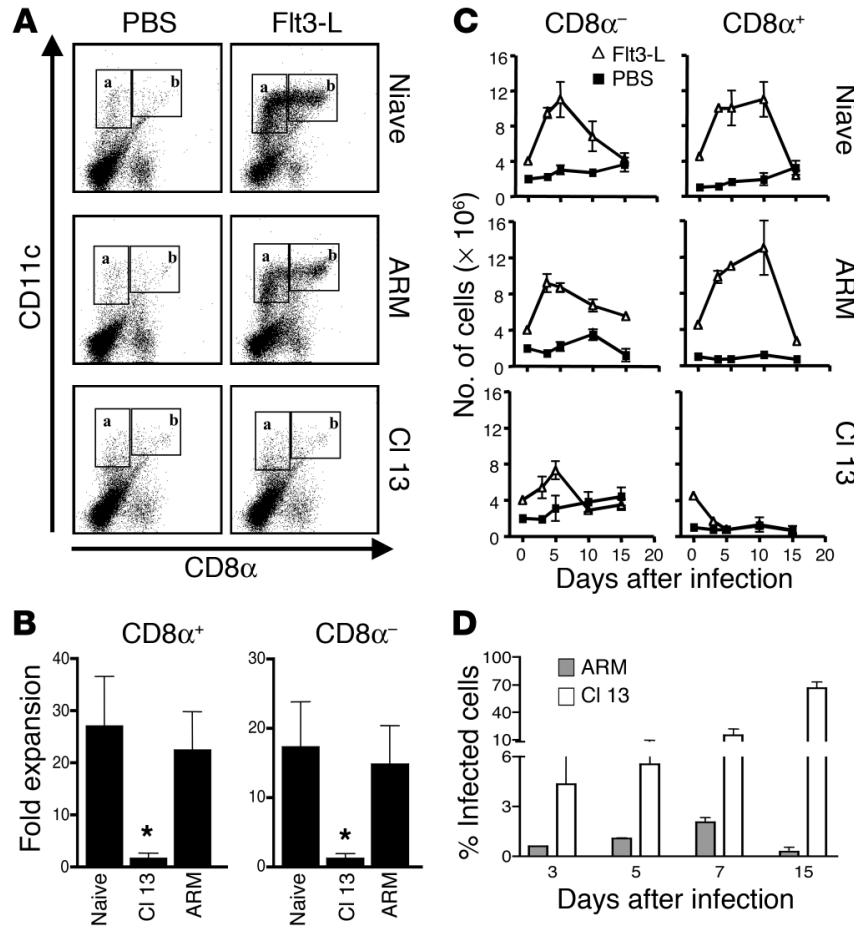

day 10 to 12 after infection from blood and spleen. In contrast, $\mathrm{Cl}$ 13 -infected mice maintained a viral load of $10^{4}$ to $10^{6} \mathrm{PFU}$ until day 60 after infection, at which point $30 \%$ of the mice started to clear the virus. By day 120 all $\mathrm{Cl} 13$-infected mice cleared the infection from the sera and spleen. These data indicate that reduction and subsequent recovery of MHC class II, MHC class I, CD40, CD86, and $\mathrm{CD} 80$ molecules was associated with the host's ability to clear $\mathrm{Cl} 13$ virus and terminate the infection.

Cl 13 LCMV infection impairs DC function. To test whether the ability of $\mathrm{Cl} 13$ virus to reduce the surface expression of antigen-presenting and costimulatory molecules paralleled an inability of infected DCs to stimulate the proliferation of $\mathrm{T}$ cells, we investigated whether splenocytes from virus-infected mice could induce the proliferation of T cells in a primary allogeneic MLR. Splenocytes from mice infected with LCMV Cl 13 or ARM at 3, 5, 7, 10, 15, 30, 60, and 120 days after infection were collected and incubated with allogeneic $T$ cells for 4 days. As shown in Figure 1D, splenocytes from Cl 13-infected mice were not efficient at stimulating a primary MLR, whereas splenocytes from ARM-infected mice were as effective as those from uninfected mice at all timepoints. We analyzed $\mathrm{T}$ cell proliferation at daily intervals during the 4-day assay (data not shown). Splenocytes were obtained from mice infected with $\mathrm{Cl} 13$ or ARM for 10, 30, and 60 days. At no time during the 4-day culture of these samples was $\mathrm{T}$ cell proliferation observed when splenocytes from $\mathrm{Cl} 13$-infected mice were used. These data demonstrate that infection with $\mathrm{Cl} 13$ resulted in a functional deficit in APCs that aborts a primary MLR.

$L C M V C l$ 13-infected mice are refractory to Flt3-L treatment. Since splenic DCs from mice infected with LCMV Cl 13 showed a reduced expression of molecules that signify maturation, it was important to determine whether LCMV infection had an effect on DC precursors. To induce the proliferation of DC precursors in vivo, we injected an optimal dose of Flt3-L (10 $\mu$ g/day for 10 days) (38), starting 15 days after infection with ARM or $\mathrm{Cl} 13$ viruses. These mice were sacrificed after the tenth day of Flt3-L treatment. Their spleens were

\section{Figure 2}

Splenic CD8 $\alpha^{+}$and CD8 $\alpha^{-}$DCs do not expand after Flt3-L treatment in Cl 13-infected mice. (A) Dot plots show double staining for CD11c and CD8 $\alpha$ molecules on splenocytes from mice treated with Flt3-L or PBS, which was initiated at day 15 after infection. Boxes labeled a denote CD11 $\mathrm{c}^{+} \mathrm{CD} 8 \alpha^{-}$(myeloid) DCs, and boxes labeled b denote CD $11 \mathrm{c}^{+} \mathrm{CD} 8 \alpha^{+}$ (lymphoid) DCs. (B) The fold expansion of CD11 $\mathrm{C}^{+} \mathrm{CD} 8 \alpha^{+}$(boxes labeled b) and $\mathrm{CD} 11 \mathrm{C}^{+} \mathrm{CD} 8 \alpha^{-}$(boxes labeled a) DCs is plotted for naive, $\mathrm{Cl}$ 13-infected, and ARM-infected mice, calculated as indicated in Methods. (C) DCs were isolated from spleens of mice that were treated with either PBS (filled squares) or Flt3-L (open triangles) for 15 days. The treatment began 5 days prior to infection and continued for an additional 10 days. Mice were sacrificed at days $0,5,10$, and 15 after infection. Day 0 after infection corresponds to day 5 of Flt3-L treatment, and day 10 after infection represents the end of Flt3-L treatment. Flow cytometric analyses were performed to determine the number of splenic CD11c ${ }^{+}$CD $8 \alpha^{-}$(myeloid) and CD11 $\mathrm{c}^{+} \mathrm{CD} 8 \alpha^{+}$(lymphoid) DCs. The populations were gated as shown in Figure 3A. The absolute number of CD11 $\mathrm{c}^{+} \mathrm{CD} 8 \alpha^{-}$and $\mathrm{CD} 11 \mathrm{c}^{+} \mathrm{CD} 8 \alpha^{+}$ DCs are plotted for naive, ARM-infected, and $\mathrm{Cl} 13$-infected mice. The data are representative of two independent experiments using nine mice per group. (D) The percentage of infected BMCs was calculated at days 3, 5, 7, and 15 after infection in Cl 13-infected (white bars) and ARM-infected (gray bars) mice. BMCs were harvested at the indicated timepoints, stained with an LCMV NP-specific antibody directly conjugated to Alexa 488 , and analyzed by flow cytometry.

then harvested and used as a source of lymphoid $\left(\mathrm{CD} 11 \mathrm{c}^{+} \mathrm{CD} 8 \alpha^{+}\right)$ and myeloid $\left(\mathrm{CD} 11 \mathrm{c}^{+} \mathrm{CD} 8 \alpha^{-}\right) \mathrm{DCs}$ for analysis by flow cytometry. Uninfected mice treated with Flt3-L showed a 15-fold increase in the number of CD $11 \mathrm{c}^{+} \mathrm{DCs}$, which were predominantly CD $8 \alpha^{+}$(Figure 2, A and B). Similarly, DCs from ARM-infected mice treated with Flt3-L showed a 20-fold expansion (Figure 2, A and B). In contrast, DCs harvested from $\mathrm{Cl} 13$-infected mice did not respond to Flt3-L treatment, as evidenced by the lack of either CD $8 \alpha^{+}$or $C D 8 \alpha^{-} \mathrm{DC}$ expansion. Thus, $\mathrm{Cl} 13$-infected mice were refractory to the stimulatory effect Flt3-L normally has on hematopoietic progenitors of both the myeloid and lymphoid lineage.

Because LCMV Cl 13 targets DCs in vivo, we next asked whether expansion of DCs before infection would alter the immunosuppressive phenotype observed with this variant. Mice were treated daily with Flt3-L for 15 days, starting 5 days preceding inoculation with either LCMV Cl 13 or LCMV ARM and finishing 10 days after initiating the infection. Spleens and BMCs were obtained from mice that were either uninfected, infected with ARM, or infected with $\mathrm{Cl} 13$ at $0,3,5,10$, and 15 days after virus challenge, which corresponded to days 5, 8, 10, 15, and 20 after Flt3-L treatment. DCs from uninfected mice showed expansion of their CD $8 \alpha^{+}$and CD8 $\alpha^{-}$subsets, with a peak increase at 10 days after Flt3-L treatment and a rapid decline thereafter (Figure $2 \mathrm{C}$ ). Like uninfected mice, LCMV ARM-infected mice had an expansion of CD $8 \alpha^{+}$and $\mathrm{CD} 8 \alpha^{-}$DC subsets with similar kinetics. In contrast, Cl 13 -infected mice failed to significantly expand either their CD $8 \alpha^{+}$or CD $8 \alpha$ DC subsets (Figure 2C). Since Flt3-L also stimulates the generation and expansion of $\mathrm{NK}$ cells $\left(\mathrm{CD}^{-}{ }^{-} \mathrm{NK} 1.1^{+}\right)$(39), we calculated the numbers of CD3-NK1.1 $1^{+}$cells in the spleens of mice treated with Flt3-L. A significant expansion of NK cells was observed in the spleens of naive or ARM-infected mice treated with Flt3-L (up to tenfold compared with non-Flt3-L controls), but no such NK cell expansion occurred in spleens of $\mathrm{Cl} 13$-infected mice treated with Flt3-L (data not shown). 
Because viral infection of progenitors can interfere with their development, we next determined the numbers of BMCs infected by either $\mathrm{Cl} 13$ or ARM (Figure 2D). According to flow cytometric analyses, at least $5 \%$ of BMCs in Cl 13-infected mice displayed the NP of LCMV in their cytoplasm at day 3 after infection, with an increase to $65 \%$ by day 15 after infection (Figure 2D). In contrast, BMCs from mice inoculated with LCMV ARM were not infected at any time. The infection of BMCs by $\mathrm{Cl} 13$ in vivo suggests that this virus may have a direct effect on hematopoietic precursors. Since $\mathrm{Cl} 13$ but not $\mathrm{ARM}$ virus infects BMCs, the results also suggest that BMCs likely express the cellular receptor $\alpha-D G$.

LCMV interferes with DC development in vitro. To further document the interference of $\mathrm{Cl} 13$ infection with the development of hematopoietic progenitors, we used an in vitro system in which BMCs were cultured with a second hematopoietic cytokine, GM$\mathrm{CSF}$, and infected with LCMV Cl 13. The expression of CD11c and CD11b was appraised by flow cytometry at 3, 5, 7, 10, and 11 days of culture (Figure 3A). Uninfected cultures underwent a dramatic increase in the percentage of $\mathrm{CD} 11 \mathrm{c}^{+}$cells over time, from $1.5 \%$ before culture (data not shown) to $96 \%$ by day 10 (Figure 3A). In stark contrast, $\mathrm{Cl} 13$-infected BMCs had a peak of $41 \%$ CD $11 \mathrm{c}^{+}$cells by day 7 in culture, and the level then declined dramatically to $13 \%$ by day 11 (Figure 3A, Cl 13). This decline in the percentage of CD $11 c^{+}$cells was not observed in cultures infected with LCMV ARM and was associated with the number of CD11 $\mathrm{c}^{+}$cells infected (Figure 3B). LCMV Cl 13 infected approximately $50 \%$ of all CD $11 \mathrm{c}^{+}$cells as well the majority of CD11 $\mathrm{c}^{-}$cells at day 11 after culture. In contrast, LCMV ARM infected less than $14 \%$ of CD $11 \mathrm{c}^{+}$cells by this same timepoint. The DCs obtained from cultures infected with $\mathrm{Cl}$ 13 (but not ARM) were nonfunctional, as evidenced by their inability to stimulate allogeneic T cells (Figure 3C). Finally, the mechanism by which $\mathrm{Cl} 13$ disrupts DC differentiation and function does not appear to involve the induction of DC apoptosis. The percentage of annexin $\mathrm{V}$-positive DCs was similar between uninfected and Cl 13-infected cultures, respectively, at day 3 (9.8\% vs. $12.0 \%)$, day 6 (24.4\% vs. $29.0 \%$ ), and day 10 (31.5\% vs. $23.5 \%$ ). Collectively, these data suggest that viral infection of BMCs was required to inhibit the development and functionality of $\mathrm{CD} 11 \mathrm{c}^{+}$cells in these cultures.

\section{Figure 3}

$\mathrm{Cl} 13$ infection of BMCs in vitro inhibits the generation of CD11C $\mathrm{C}^{+} \mathrm{DCs}$. (A) Dot plots show CD11C and CD11b expression for uninfected and CI 13-infected BMCs at days 3, 5, 7, 10, and 11 of culture with GM-CSF. The boxes denote the percentage of CD11 $\mathrm{c}^{+} \mathrm{DCs}$ in the cultures. Note the reduction in the percentage of $\mathrm{CD}_{11 \mathrm{c}^{+}}$cells in $\mathrm{Cl} 13$-infected cultures when compared with uninfected cultures at all timepoints. The data shown are representative of five independent experiments. (B) The per-

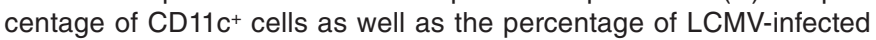

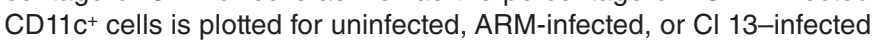
cultures at day 11 . Data are represented as the mean \pm SD. Statistical differences were determined using a one-way ANOVA $(P<0.05)$. Asterisks denote a statistical difference from uninfected cultures. (C) The allostimulatory capacity of uninfected, ARM-infected, or Cl 13-infected BM DCs was evaluated at day 11 after culture. Log-serial dilutions (ranging from $10^{2}$ to $10^{5}$ ) of DCs were irradiated and used as stimulator cells for allogeneic T cells from BALB/c $\left(H-2^{d}\right)$ mice at a T cell/DC ratio of $5: 1$ in the MLR. Proliferation was measured in $\mathrm{cpm}$ after $\left[{ }^{3} \mathrm{H}\right]$ thymidine incorporation. (D) Fresh BMCs were isolated from $\mathrm{Cl} 13$ - or ARM-infected mice at day 15 after infection and grown for 11 days in the presence of GM-CSF. Dot plots show CD11c and CD11b expression. The boxes denote the percentage of CD11 $\mathrm{c}^{+} \mathrm{DCs}$ in the cultures.
To clarify whether $\mathrm{Cl} 13$ could infect and disrupt cells at multiple stages along a development pathway, BMCs cultured with GM-CSF were infected at days 5, 7, and 10 of culture. Following $\mathrm{Cl} 13$ infection, cultures were continued in GM-CSF until day 11, at which point the frequency of CD $11 \mathrm{c}^{+}$cells as well as the number of infected cells (i.e., containing virus NP) were analyzed by flow cytometry. Compared with uninfected cultures, those with the virus added at day 5,7 , or 10 after culture developed similar numbers of CD $11 c^{+}$ cells (data not shown), which contrasted with the significant reduction of CD $11 c^{+}$cells when virus was added on day 0 or day 3 . The percentage of cells infected after receiving virus on day 5 or day 7 was approximately $75 \%$ but decreased to $20 \%$ when cultures were infected at day 10. Clearly, although $\mathrm{Cl} 13$ can infect DCs at all stages along the developmental pathway, infection must occur at an early stage to affect the development of CD $11 \mathrm{c}^{+}$cells.

Since the MOI used for the in vitro infections may not have reflected the physiologic viral load of BMCs infected in vivo, we next isolated BM from mice 15 days after infection with $\mathrm{Cl} 13$ or ARM and cultured them with GM-CSF; we did the same with BMCs from uninfected mice. The cells were once again harvested and analyzed at day 11 after culture. The percentage of CD $11 c^{+}$cells produced from the BM obtained from $\mathrm{Cl} 13$-infected mice was significantly reduced and resembled that from $B M$ cultures infected in vitro with $\mathrm{Cl} 13$ (Figure 3D). Similarly, cultures derived from BM of mice
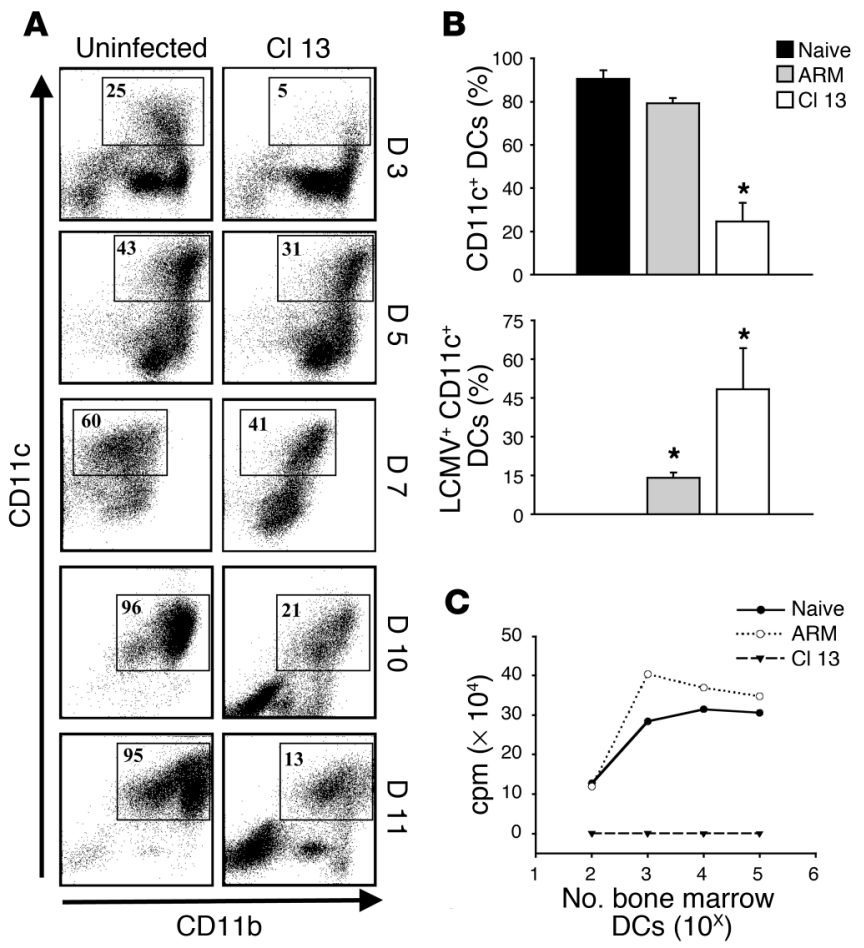

D ARM infected in vivo

Cl 13 infected in vivo
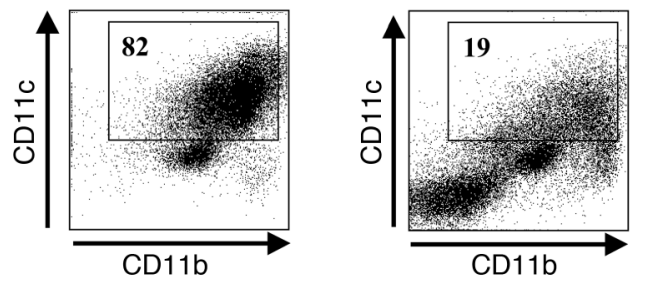

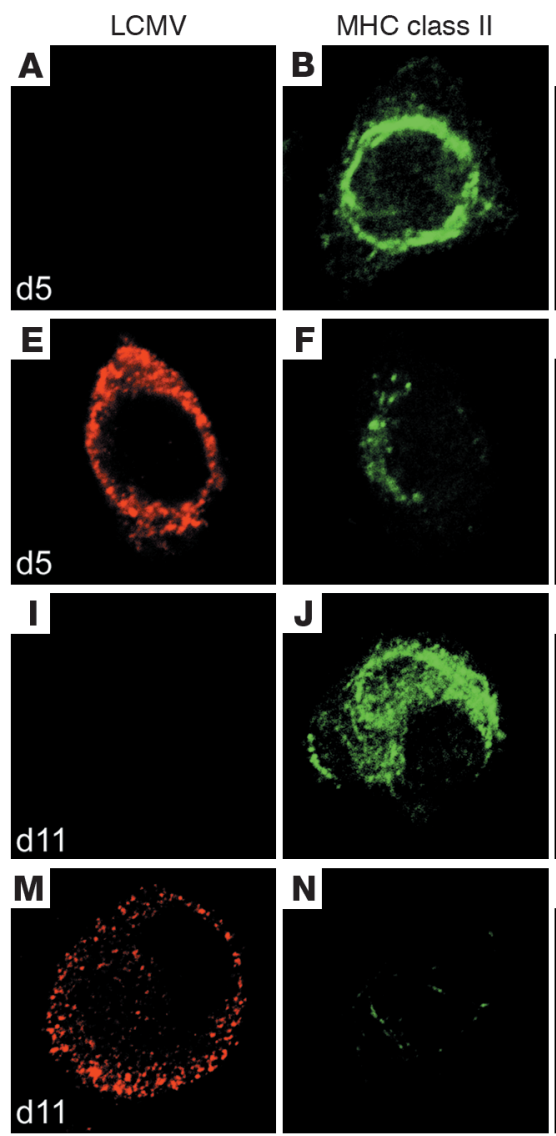

CD11c
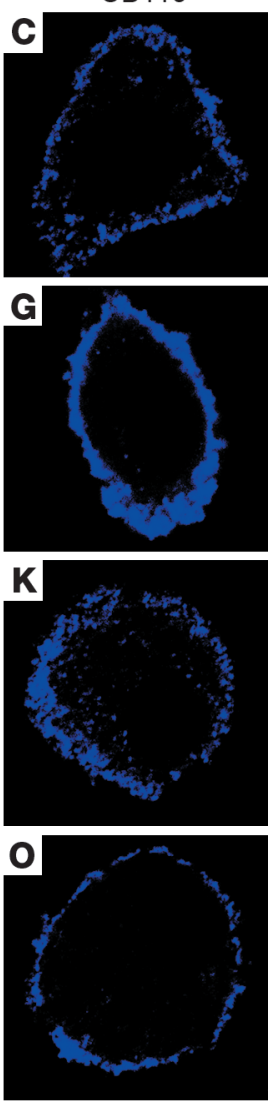

Merge
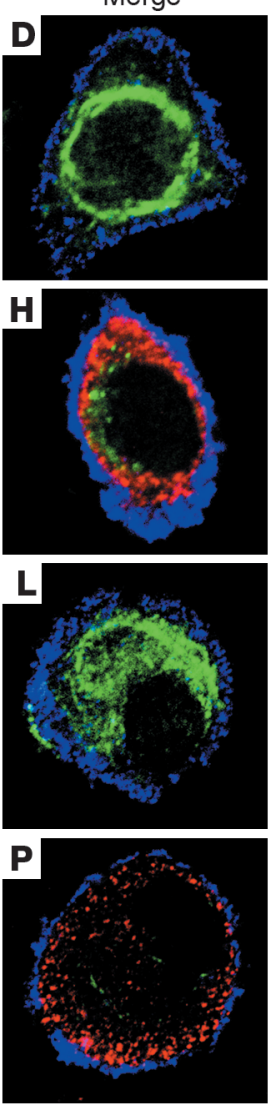

\section{Figure 4}

$\mathrm{Cl} 13$ infection inhibits the expression of MHC class II molecules on CD11c $\mathrm{C}^{+} \mathrm{DC}$. Confocal microscopy was used to analyze the expression of MHC class II molecules (green), CD11c (blue), and viral NP (red) on BMCs stimulated with GM-CSF in vitro. LCMV indicates cells infected with $\mathrm{Cl}$ 13. Panels $\mathbf{A}-\mathbf{D}$ show uninfected BMCs after 5 days of culture. The same timepoint is shown in panels $\mathbf{E}-\mathbf{H}$ for $\mathbf{C l}$ 13-infected cells. Note the perinuclear distribution of MHC class II in uninfected DCs at day 5. A similar distribution was observed in $\mathrm{Cl}$ 13-infected DCs at this timepoint; however, the intensity of staining was significantly reduced. At day 11, MHC class II was detected on the plasma membrane of CD11 $\mathrm{C}^{+} \mathrm{DCs}$ in the uninfected cultures (I-L) but not on Cl 13-infected DCs (M-P). The micrographs are representative of at least three independent experiments in which a minimum of ten DCs was analyzed. infected with ARM in vivo showed a lack of virus replication and the same CD11c/CD11b distribution as BMCs harvested from uninfected mice, indicating that the inhibition of DC development requires viral replication in BMCs. In summary, these experiments provide three important results. First, $\mathrm{Cl} 13$ inhibits the development, differentiation, and function of CD $11 \mathrm{c}^{+}$cells. Second, the effect observed in vitro is biologically meaningful as it parallels the outcome seen with in vivo infection. Third, the inhibition of development and differentiation of $\mathrm{CD} 11 \mathrm{c}^{+}$cells is dependent on and correlates directly with viral infection of these cells.

Cl 13 infection inhibits expression of MHC class II molecules on DCs. In BM DC cultures, the addition of stimuli such as the bacterial product LPS triggers differentiation of immature into mature DCs; this is accompanied by the migration of MHC II molecules from an intracellular compartment to the plasma membrane (40). This process allows DCs to activate $\mathrm{T}$ cells $(41,42)$. We next studied the expression and distribution of MHC class II molecules on uninfected and LCMV Cl 13-infected CD11 ${ }^{+}$DCs by confocal microscopy after 5 days of culture (defined as "early" or immature phenotype) and after LPS stimulation at day 11 of culture (defined as "late" or mature phenotype). As expected, the majority of the uninfected DCs at day 5 contained abundant intracellular MHC class II molecules, primarily in the perinuclear region. At the same time, $\mathrm{Cl} 13$-infected CD $11 \mathrm{c}^{+}$cells showed a significant reduction in the intensity (i.e., numbers) of class II molecules, indicating an association between virus replication and a decreased expression of MHC class II molecules (Figure 4). After LPS stimulation (day 11) of uninfected CD $11 c^{+}$DCs, the level of MHC class II substantially increased in the cytoplasm, and MHC molecules migrated to the plasma membrane.
In contrast, $\mathrm{Cl} 13$-infected $\mathrm{CD} 11 \mathrm{c}^{+} \mathrm{DCs}$ showed barely detectable levels of MHC class II molecules in the intracellular compartment and on the plasma membrane. These results were duplicated in at least ten DCs obtained from three different experiments, indicating the reproducibility of the phenotype (Figure 4). These data indicate that the presence of $\mathrm{Cl} 13$ in DC cultures interferes with the production of MHC class II molecules. The consequence is the inhibition of MHC function required for maturation and antigen-presenting capacity $(41,42)$.

IFN- $\alpha / \beta$ inbibits the development and differentiation of $C D 11 c^{+} D C s$ in Cl 13-infected mice. A role for cytokines, especially the IFN family, has been reported for several phenomena associated with LCMV infection and DC function (43-45). Type 1 IFNs (IFN- $\alpha$ and IFN- $\beta$ ) have been proposed to function in a constitutive mode to maintain homeostasis, particularly in the hematopoietic system $(46,47)$. In order to evaluate the role, if any, of these cytokines in the inhibition of $\mathrm{CD} 11 \mathrm{c}^{+}$cell development in $\mathrm{Cl} 13$-infected mice, we persistently infected mice with a genetic disruption of IFN- $\alpha / \beta$ receptor (IFN- $\alpha / \beta \mathrm{R}^{0 / 0}$ mice) with $\mathrm{Cl} 13$ and then treated them with Flt3-L. IFN- $\alpha / \beta R^{0 / 0}$ or $129 / \mathrm{SvEv}$ control mice were injected with 10 $\mu \mathrm{g}$ of Flt3-L per day for 10 days starting 15 days after Cl 13 infection, similar to the protocol used for C57BL/6 mice (see Figure 2). Mice were sacrificed after the tenth day of Flt3-L treatment, and the numbers of $\mathrm{CD} 11 \mathrm{c}^{+} \mathrm{CD} 8 \alpha^{+}$or $\mathrm{CD} 11 \mathrm{c}^{+} \mathrm{CD} 8 \alpha^{-}$cells in the spleen were analyzed by flow cytometry. Infection of $129 / \mathrm{SvEv}$ control mice with $\mathrm{Cl}$ 13 resulted in a reduced expansion of both $\mathrm{CD} 8 \alpha^{+}$and $\mathrm{CD} 8 \alpha^{-} \mathrm{DCs}$ following Flt3-L treatment (Figure 5), similar to the pattern observed in C57BL/ 6 mice. Interestingly, $\mathrm{Cl} 13$ infection of mice deficient in the IFN- $\alpha / \beta$ receptor resulted in a normal expansion of 
$\mathrm{CD} 8 \alpha^{+}$DCs when compared with uninfected controls (Figure 5). However, CD8 $\alpha^{-}$DCs remained reduced in number. These data suggest that while $\mathrm{Cl} 13$ inhibits the development and differentiation of CD $8 \alpha^{+}$DCs through a mechanism involving IFN- $\alpha / \beta$, it is likely that additional factors contribute to the impairment of CD $8 \alpha^{-}$DCs.

\section{Discussion}

Here we report mechanistically how a virus can suppress the immune response. The immunosuppressive LCMV variant $\mathrm{Cl} 13$ selectively infects splenic DCs of the adult host, resulting in severe impairment of antigen presentation. In addition, the virus also targets $\mathrm{BM}$ progenitors and interferes with their development. This requires at least two events: the direct infection of BM progenitors and the secretion of IFN- $\alpha / \beta$. The mechanism by which LCMV causes immunosuppression likely applies to other viruses that compromise the immune system and establish chronic or persistent infections, including those occurring in humans.

Our studies indicate that DCs purified from the spleens of $\mathrm{Cl}$ 13-infected mice have a reduced expression of cell surface proteins involved in antigen presentation (MHC class II, MHC class I) and costimulation (CD80, CD86, and CD40). The expression of these molecules is associated with the maturation of DCs, an essential step required for generation of immune responses. CD40-CD40L interaction is important for activation of $\mathrm{CD}^{+} \mathrm{T}$ cells, and the absence of this interaction is likely to cause a deficiency in CD4 T cell responses and impair the ability of a host to resolve chronic viral infection despite an intact CD8 response (48). Additionally, the lack of costimulation via CD80 and/or CD86 may impair a developing immune response by inducing $\mathrm{T}$ cell anergy or apoptosis instead of activation. Hence, the reduced expression of CD86, CD80, and CD40 observed in the present study on both CD8 $\alpha^{+}$and CD8 $\alpha^{-}$DCs from LCMV $\mathrm{Cl} 13$-infected mice likely aborts or deflates the immune response, which in part explains the observed immunosuppressive phenotype. Additionally, antigen-presenting machinery (i.e., MHC class I and class II) was reduced on both DC subsets during $\mathrm{Cl} 13$ virus infection, with a more pronounced reduction observed on CD8 $\alpha^{+}$DCs. The defect in antigen presentation is likely to have a profound effect on the priming and development of a cellular immune response. This strategy used by the virus to thwart host immune defenses is further complemented by the virus's ability to inhibit maturation of DCs. The end result is the creation of a time window that favors virus replication by dampening the development of the antiviral adaptive immune response required to terminate the infection. During this interval, the virus-infected DC pool continues to accumulate and further impair DC function. In our study, the deficit in DC activity persists over an extended period after virus clearance, as evidenced by the failure of DCs from $\mathrm{Cl}$ 13-infected mice at 120 days to induce the proliferation of allogeneic T cells, although virus was cleared from the host by day 60 . This disassociation between LCMV clearance and prolonged immunosuppression is reminiscent of observations with measles virus (49-51). Measles virus infection impairs the host's T cell-mediated response to tuberculin and other antigens, and this impairment usually persists for a number of months after measles virus is cleared from the patient (52). Measles virus also infects DCs $(4,5,53,54)$. However, the precise mechanism or mechanisms underlying the immunosuppression remain undefined.

By targeting BMCs, the immunosuppressive LCMV variant $\mathrm{Cl} 13$ uses an additional mechanism to interfere with the development of an efficient immune response. Injection of mice with the hematopoi- etic growth factor Flt3-L allows one to evaluate the effects of the $\mathrm{Cl}$ 13 virus on DC and NK progenitors in vivo. Flt3-L is a hematopoietic cytokine that acts on myeloid/lymphoid DC progenitor cells and induces the expansion of both DC and NK cells (55). After Flt3-L treatment, mice infected for 15 days with $\mathrm{Cl} 13$ virus failed to expand both $\mathrm{CD} 8 \alpha^{+}$and $\mathrm{CD} 8 \alpha^{-}$DCs, whereas uninfected controls or mice infected with the nonimmunosuppressive LCMV ARM showed a 15to 20-fold expansion in the number of splenic DCs. Several studies have identified Flt3-L and c-kit ligand as the only growth factors that have a direct effect on primitive murine and human hematopoietic progenitor cells (56). Moreover, the expression of the Flt3-L receptor appears confined to primitive progenitor cells rather than committed myeloid or lymphoid progenitors (57). The lack of DC expansion observed in $\mathrm{Cl} 13$-infected mice likely results from viral interference with the Flt3-L signaling pathway or from some other virus-induced alteration of pluripotent stem cell function. The precise mechanism (or mechanisms) involved in this defect is unknown and is the focus of current investigations.

The inhibitory effect $\mathrm{Cl} 13$ has on DC progenitor cells appears to be associated with its ability to infect BMCs. However, it is likely that factors in addition to the massive infection of BMCs can interfere with the differentiation of progenitors. For example, at a time when

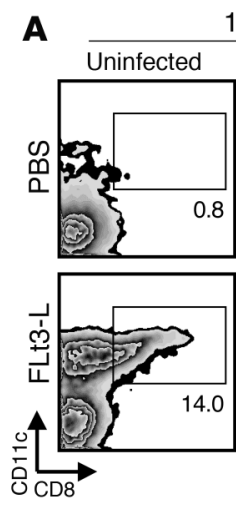

$\mathbf{B}$ 129

IFNR- $\alpha / \beta \mathrm{KO}$

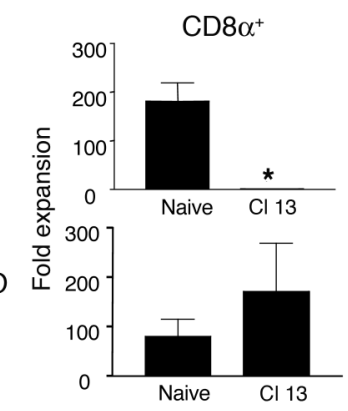

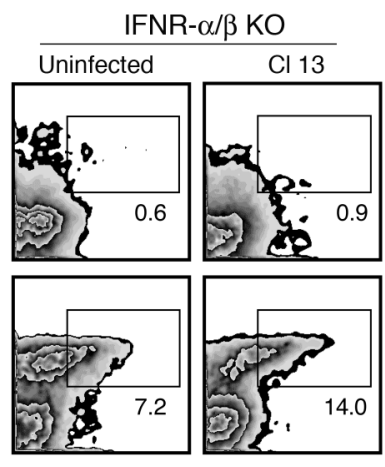

$\mathrm{CD} 8 \alpha^{-}$

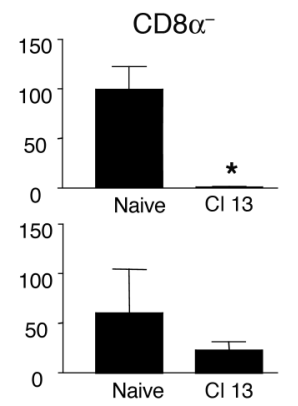

Figure 5

IFN- $\alpha / \beta R^{0 / 0}$ mice infected with $\mathrm{Cl} 13$ expand $\mathrm{DCs}$ in response to Flt3-L treatment. Splenic DCs were isolated from uninfected or $\mathrm{Cl}$ 13-infected IFN- $\alpha / \beta R^{0 / 0}$ and $129 / \mathrm{SvEv}$ mice treated for 10 days with Flt3-L (see Figure 3). The Flt3-L treatment was initiated at day 15 after infection. (A) Dot plots show $\mathrm{CD} 11 \mathrm{C}^{+} \mathrm{CD} 8 \alpha^{+}$and $\mathrm{CD} 11 \mathrm{C}^{+} \mathrm{CD} 8 \alpha^{-} \mathrm{DCs}$ in mice treated with PBS or Flt3-L. Boxes denote the percentage of CD11 $c^{+} C D 8 \alpha^{+} D C s$. Note the normal expansion of CD11 $\mathrm{C}^{+} \mathrm{CD} 8 \alpha^{+} \mathrm{DC}$ in Flt3-L-treated IFN- $\alpha / \beta \mathrm{R}^{0 / 0}$ mice infected with $\mathrm{Cl} 13$. (B) The fold expansion of both $\mathrm{CD} 11 \mathrm{c}^{+} \mathrm{CD} 8 \alpha^{+}$ and $\mathrm{CD} 11 \mathrm{C}^{+} \mathrm{CD} 8 \alpha^{-} \mathrm{DC}$ is plotted for naive and $\mathrm{Cl} 13$-infected mice. The fold expansion was calculated by dividing the absolute number of each DC subset in Flt3-L-treated mice by the absolute number of cells in PBStreated mice. Data are presented as the mean \pm SD. Statistical differences denoted by asterisks were determined using a Student $t$ test $(P<0.05)$. 
fewer than $10 \%$ of BMCs were infected (i.e., day 5 after infection), an inhibitory effect on DC development was noted (see Figure 2). Thus, $\mathrm{Cl} 13$ may have the capacity to impair the expansion of progenitor cells by two means. First, Cl 13 may directly disrupt cell differentiation by selectively inhibiting the transcription of specific host genes. There are multiple examples for this activity involving cells of the immune, endocrine, and nervous systems. In these examples, the virus can abort the differentiation (luxury) function of a cell without affecting its vital "housekeeping" functions or inducing cell death (58-60). The second mechanism by which $\mathrm{Cl} 13$ may interfere with progenitor cell differentiation is through the indirect induction of an inhibitory factor or factors. In support of this second mechanism, we noted that IFN- $\alpha / \beta$ induced by $\mathrm{Cl} 13$ inhibits DC generation in vivo. Mice that were unable to respond to IFN- $\alpha / \beta$ because of an inability to express the appropriate receptor showed a normal expansion of the CD8 $\alpha^{+}$DC subset following Flt3-L treatment. In contrast, the number of CD $8 \alpha^{-}$DCs remained significantly reduced in IFN- $\alpha / \beta \mathrm{R}^{0 / 0}$ mice. This finding suggests that factors other than IFN- $\alpha / \beta$ play a role in the development of CD $8 \alpha^{-}$DCs. Hence, IFN- $\alpha / \beta$ appears to be a potent inhibitor of proliferation/maturation in normal BM-derived DCs. The role for IFN- $\alpha / \beta$ proposed in this manuscript may apply to other viruses such the Lassa or Junin arenaviruses, Dengue fever virus, and Ebola virus. Infection with these viruses results in high concentrations of IFN- $\alpha / \beta$ in the serum, and the magnitude and the duration of circulating IFN- $\alpha / \beta$ correlate directly with the severity and the evolution of the disease (61-65).

The in vivo inhibition of DC expansion during $\mathrm{Cl} 13$ virus infection also occurred in vitro when the cytokine GM-CSF was used to promote DC differentiation from hematopoietic progenitors (66). Using a different cytokine, we showed that the deficit induced by $\mathrm{Cl}$ 13 was not simply restricted to the Flt3-L signaling pathway. The infection of BMCs by $\mathrm{Cl} 13$ virus in vitro interferes significantly with the development of CD $11 \mathrm{c}^{+}$DCs, and the differences observed between uninfected and infected cultures became more prominent as the number of cells infected in the culture increased. In addition, the disruption in DC development was observed only when the infection was established early in the cultures. When the virus was added at day 7 (intermediate DCs) or day 10 (mature DCs), DC development was unimpaired despite the fact that large numbers of cells became infected. These results indicate that DC precursors must be infected at an early stage in development to interfere with their maturation. To establish the relevance of our in vitro observations, BM cultures stimulated with GM-CSF were established from mice infected with either $\mathrm{Cl} 13$ or ARM. Importantly, a similar reduction in the development of CD $11 \mathrm{c}^{+}$DCs was observed when cultures were derived from $\mathrm{Cl} 13$-infected mice. In contrast, $\mathrm{BMCs}$ from mice infected by the parental ARM virus showed normal numbers of CD $11 c^{+}$DCs. Thus, $\mathrm{Cl} 13$ is able to infect a sufficient number of BM progenitors in vivo to interfere with their development into mature DCs following GM-CSF stimulation in vitro.

Although DC maturation is accompanied by an increased expression of several surface molecules that facilitate $\mathrm{T}$ cell stimulation, the regulation of MHC class II transport plays a central role in developmentally restricting antigen presentation $(41,42)$. As DCs develop, class II molecules localize first in late endocytic compartments and later move to the cell surface (67). To gain insights into the role of $\mathrm{Cl} 13$ in disrupting this process, we focused on the expression and localization of MHC class II molecules on developing CD $11 \mathrm{c}^{+}$DCs in BM cultures. Experiments using triple staining and confocal microscopy (Figure 4) at both early and late times during the development of DCs clearly showed a marked reduction in the expression of MHC class II molecules on infected CD $11 c^{+}$DCs. These observations indicate that $\mathrm{Cl} 13$ virus interferes with either the transcription or translation of MHC class II molecules. The resultant lack of MHC II molecules ultimately contributes to the inability of the infected DC to function properly. It is of note that interference with MHC class II surface expression has also been reported for HIV and cytomegalovirus infections $(68,69)$.

In conclusion, our findings indicate that LCMV Cl 13 infection disrupts the immune system and escapes immunosurveillance using a multifaceted strategy. By one mechanism, the virus infects hematopoietic precursors and induces the production of IFN- $\alpha / \beta$, which interferes with DC development and subsequently reduces the number of functional APCs. Using a second mechanism, the virus infects CD11 $\mathrm{c}^{+}$DCs and inhibits their maturation by interfering with various antigen-presenting and costimulatory molecules. The events and strategies described here with LCMV in its natural murine host likely apply to a variety of viruses that infect humans and cause immunosuppression and/or persistent infection.

\section{Acknowledgments}

This work was supported by US Public Health Service grants AI09484 and AI45927 as well as NIH training grant AG-00080 to D.B. McGavern. We thank Immunex Corp. for the human recombinant Flt3-L used in these studies.

Received for publication October 8, 2003, and accepted in revised form December 2, 2003.

Address correspondence to: Noemí Sevilla, Centro de Biología Molecular Severo Ochoa, Universidad Autónoma de Madrid, Cantoblanco, Madrid 28049, Spain. Phone: 34-91-397-8477; Fax: 34-91397-4799; E-mail: nsevilla@cbm.uam.es.
1. Bancahereau, J., and Steinman, R.M. 1998. Dendritic cells and the control of immunity. Nature. 392:245-252.

2. Steinman, R.M. 1991. The dendritic cell system and its role in immunogenicity. Annu. Rev. Immunol. 9:271-296.

3. Knight, S.C., and Patterson, S. 1997. Bone marrowderived dendritic cells, infection with human immunodeficiency virus, and immunopathology. Annu. Rev. Immunol. 15:593-615.

4. Fugier-Vivier, I., et al. 1997. Measles virus suppresses cell-mediated immunity by interfering with the survival and functions of dendritic and T cells. J. Exp. Med. 186:813-823.

5. Grosjean, I., et al. 1997. Measles virus infects human dendritic cells and blocks their allostimulatory properties for CD4+ T cells. J. Exp. Med. 186:801-812.

6. Schnorr, J.J., et al. 1997. Induction of maturation of human blood dendritic cell precursors by measles virus is associated with immunosuppression. Proc. Natl. Acad. Sci. U. S. A. 94:5326-5331.

7. Andrews, D.M., Andoniou, C.E., Granucci, F., Ricciardi-Castagnoli, P., and Degli-Esposti, M.A. 2001. Infection of dendritic cells by murine cytomegalovirus induces functional paralysis. Nat. Immunol. 2:1077-1084

8. Moutaftsi, M., Mehl, A.M., Borysiewicz, L.K., and Tabi, Z. 2002. Human cytomegalovirus inhibits maturation and impairs function of monocyte-derived dendritic cells. Blood. 99:2913-2921.
9. Raftery, M.J., et al. 2001. Targeting the function of mature dendritic cells by human cytomegalovirus: a multilayered viral defense strategy. Immunity. 15:997-1009.

10. Kruse, M., et al. 2000. Mature dendritic cells infected with herpes simplex virus type 1 exhibit inhibited T-cell stimulatory capacity. J. Virol. 74:7127-7136.

11. Ho, L.J., et al. 2001. Infection of human dendritic cells by dengue virus causes cell maturation and cytokine production. J. Immunol. 166:1499-1506.

12. Wu, S.J., et al. 2000. Human skin Langerhans cells are targets of dengue virus infection. Nat. Med. 6:816-820.

13. Borrow, P., et al. 1997. Antiviral pressure exerted by HIV-1-specific cytotoxic T lymphocytes (CTLs) dur- 
ing primary infection demonstrated by rapid selection of CTL escape virus. Nat. Med. 3:205-211.

14. von Herrath, M.G., Guerder, S., Lewicki, H., Flavell, R.A., and Oldstone, M.B. 1995. Coexpression of B7-1 and viral ("self") transgenes in pancreatic beta cells can break peripheral ignorance and lead to spontaneous autoimmune diabetes. Immunity. 3:727-738.

15. Zinkernagel, R.M., and Doherty, P.C. 1979. MHCrestricted cytotoxic T cells: studies on the biological role of polymorphic major transplantation antigens determining T-cell restriction-specificity, function, and responsiveness. Adv. Immunol. 27:51-177.

16. Pircher, H., Burki, K., Lang, R., Hengartner, H., and Zinkernagel, R.M. 1989. Tolerance induction in double specific T-cell receptor transgenic mice varies with antigen. Nature. 342:559-561.

17. Ahmed, R., and Oldstone, M.B.A. 1988. Organ specific selection of viral variants during chronic infection. J. Exp. Med. 167:1719-1724.

18. Ahmed, R., Salmi, A., Butler, L.D., Chiller, J.M., and Oldstone, M.B.A. 1984. Selection of genetic variants of lymphocytic choriomeningitis virus in spleens of persistently infected mice: role in suppression of cytotoxic $T$ lymphocyte response and viral persistence. J. Exp. Med. 160:521-540.

19. Dockter, J., Evans, C.F., Tishon, A., and Oldstone, M.B. 1996. Competitive selection in vivo by a cell for one variant over another: implications for RNA virus quasispecies in vivo. J. Virol. 70:1799-1803.

20. Evans, C.F., Borrow, P., de la Torre, J.C., and Oldstone, M.B. 1994. Virus-induced immunosuppression: kinetic analysis of the selection of a mutation associated with viral persistence. J. Virol. 68:7367-7373.

21. Sevilla, N., et al. 2000. Immunosuppression and resultant viral persistence by specific viral targeting of dendritic cells. J. Exp. Med. 192:1249-1260.

22. Ahmed, R., et al. 1991. Molecular basis of organ-specific selection of viral variants during chronic infection. J. Virol. 65:4242-4247.

23. Matloubian, M., Kolhekar, S.R., Somasundarum, T., and Ahmed, R. 1993. Molecular determinants of macrophage tropism and viral persistence: importance of single amino acid changes in the polymerase and glycoprotein of lymphocytic choriomeningitis virus. J. Virol. 67:7340-7349.

24. Villarete, L., Somasundaram, T., and Ahmed, R. 1994. Tissue-mediated selection of viral variants: correlation between glycoprotein mutation and growth in neuronal cells. J. Virol. 68:7490-7496.

25. Fung-Leung, W.P., Kundig, T.M., Zinkernagel, R.M., and Mak, T.W. 1991. Immune response against lymphocytic choriomeningitis virus infection in mice without CD8 expression. J. Exp. Med. 174:1425-1429.

26. Kagi, D., et al. 1994. Fas and perforin pathways as major mechanisms of T cell-mediated cytotoxicity. Science. 265:528-530.

27. Tishon, A., Lewicki, H., Rall, G., Von Herrath, M., and Oldstone, M.B. 1995. An essential role for type 1 interferon-gamma in terminating persistent viral infection. Virology. 212:244-250.

28. Borrow, P., Evans, C.F., and Oldstone, M.B.A. 1995. Virus-induced immunosuppression: immune system-mediated destruction of virus-infected dendritic cells results in generalized immunosuppression. J. Virol. 69:1059-1070.

29. Salvato, M., Shimomaye, E., Southern, P., and Oldstone, M.B. 1988. Virus-lymphocyte interactions. IV. Molecular characterization of LCMV Armstrong $(\mathrm{CTL}+)$ small genomic segment and that of its variant, Clone 13 (CTL-). Virology. 164:517-522.

30. Tishon, A., Borrow, P., Evans, C., and Oldstone, M.B. 1993. Virus-induced immunosuppression. 1. Age at infection relates to a selective or generalized defect. Virology. 195:397-405.
31. Althage, A., et al. 1992. Immunosuppression by lymphocytic choriomeningitis virus infection: competent effector $\mathrm{T}$ and $\mathrm{B}$ cells but impaired antigen presentation. Eur. J. Immunol. 22:1803-1812.

32. Borrow, P., Tishon, A., and Oldstone, M.B.A. 1991. Infection of lymphocytes by a virus that aborts cytotoxic T lymphocyte activity and establishes persistent infection. J. Exp. Med. 174:203-212.

33. Odermatt, B., Eppler, M., Leist, T.P., Hengatner, H., and Zinkernagel, R.M. 1991. Virus-triggered acquired immunodeficiency by cytotoxic T-cell-dependent destruction of antigen-presenting cells and lymph follicle structure. Proc. Natl. Acad. Sci. U. S. A. 88:8252-8256.

34. Smelt, S.C., et al. 2001. Differences in affinity of binding of lymphocytic choriomeningitis virus strains to the cellular receptor alpha-dystroglycan correlate with viral tropism and disease kinetics. J. Virol. 75:448-457.

35. Dutko, F.J., and Oldstone, M.B. 1983. Genomic and biological variation among commonly used lymphocytic choriomeningitis virus strains. J. Gen. Virol. 64:1689-1698.

36. Muller, U., et al. 1994. Functional role of type I and type II interferons in antiviral defense. Science. 264:1918-1921.

37. Lutz, M.B., et al. 1999. An advanced culture method for generating large quantities of highly pure dendritic cells from mouse bone marrow. J. Immunol. Methods. 223:77-92.

38. Maraskovsky, E., et al. 1997. Dramatic numerical increase of functionally mature dendritic cells in FLT3 ligand-treated mice. Adv. Exp. Med. Biol. 417:33-40.

39. Shaw, S.G., Maung, A.A., Steptoe, R.J., Thomson, A.W., and Vujanovic, N.L. 1998. Expansion of functional NK cells in multiple tissue compartments of mice treated with Flt3-ligand: implications for anti-cancer and anti-viral therapy. J. Immunol. 161:2817-2824.

40. Winzler, C., et al. 1997. Maturation stages of mouse dendritic cells in growth factor-dependent long-term cultures. J. Exp. Med. 185:317-328.

41. Pierre, P., et al. 1997. Developmental regulation of MHC class II transport in mouse dendritic cells. Nature. 388:787-792.

42. Cella, M., Engering, A., Pinet, V., Pieters, J., and Lanzavecchia, A. 1997. Inflammatory stimuli induce accumulation of MHC class II complexes on dendritic cells. Nature. 388:782-787.

43. Dalod, M., et al. 2002. Interferon alpha/beta and interleukin 12 responses to viral infections: pathways regulating dendritic cell cytokine expression in vivo. J. Exp. Med. 195:517-528.

44. McNally, J.M., et al. 2001. Attrition of bystander CD8 $\mathrm{T}$ cells during virus-induced T-cell and interferon responses. J. Virol. 75:5965-5976.

45. Ou, R., Zhou, S., Huang, L., and Moskophidis, D. 2001. Critical role for alpha/beta and gamma interferons in persistence of lymphocytic choriomeningitis virus by clonal exhaustion of cytotoxic T cells. J. Virol. 75:8407-8423.

46. Lee, C.K., Gimeno, R., and Levy, D.E. 1999. Differential regulation of constitutive major histocompatibility complex class I expression in T and B lymphocytes. J. Exp. Med. 190:1451-1464.

47. Lee, C.K., Smith, E., Gimeno, R., Gertner, R., and Levy, D.E. 2000. STAT1 affects lymphocyte survival and proliferation partially independent of its role downstream of IFN-gamma. J. Immunol. 164:1286-1292.

48. Borrow, P., et al. 1996. CD40L-deficient mice show deficits in antiviral immunity and have an impaired memory CD8+ CTL response. J. Exp. Med. 183:2129-2142.

49. Griffin, D.E., et al. 1987. In vitro studies of the role of monocytes in the immunosuppression associated with natural measles virus infections. Clin. Immunol. Immunopathol. 45:375-383.

50. Hicks, J.T., Sullivan, J.L., and Albrecht, P. 1977. Immune responses during measles infection in immunosuppressed Rhesus monkeys. J. Immunol. 119:1452-1456.

51. McChesney, M.B., and Oldstone, M.B. 1989. Virusinduced immunosuppression: infections with measles virus and human immunodeficiency virus. Adv. Immunol. 45:335-380.

52. Smithwick, E.M., and Berkovich, S. 1966. In vitro suppression of the lymphocyte response to tuberculin by live measles virus. Proc. Soc. Exp. Biol. Med. 123:276-278.

53. Schneider-Schaulies, S., Niewiesk, S., SchneiderSchaulies, J., and ter Meulen, V. 2001. Measles virus induced immunosuppression: targets and effector mechanisms. Curr. Mol. Med. 1:163-181.

54. Vidalain, P.O., Azocar, O., Rabourdin-Combe, C., and Servet-Delprat, C. 2001. Measle virus-infected dendritic cells develop immunosuppressive and cytotoxic activities. Immunobiology. 204:629-638.

55. Lyman, S.D., et al. 1993. Molecular cloning of a ligand for the flt $3 / \mathrm{flk}-2$ tyrosine kinase receptor: a proliferative factor for primitive hematopoietic cells. Cell. 75:1157-1167.

56. Lyman, S.D., and Jacobsen, S.E. 1998. c-kit ligand and Flt3 ligand: stem/progenitor cell factors with overlapping yet distinct activities. Blood. 91:1101-1134.

57. Rasko, J.E., Metcalf, D., Rossner, M.T., Begley, C.G., and Nicola, N.A. 1995. The flt3/flk-2 ligand: receptor distribution and action on murine haemopoietic cell survival and proliferation. Leukemia. 9:2058-2066.

58. Oldstone, M.B. 1989. Viruses can cause disease in the absence of morphological evidence of cell injury: implication for uncovering new diseases in the future. J. Infect. Dis. 159:384-389.

59. Oldstone, M.B. 2002. Biology and pathogenesis of lymphocytic choriomeningitis virus infection. Curr. Top. Microbiol. Immunol. 263:83-117.

60. de la Torre, J.C., and Oldstone, M.B. 1996. Anatomy of viral persistence: mechanisms of persistence and associated disease. Adv. Virus Res. 46:311-343.

61. Levis, S.C., et al. 1985. Correlation between endogenous interferon and the clinical evolution of patients with Argentine hemorrhagic fever. J. Interferon Res. 5:383-389.

62. Levis, S.C., et al. 1984. Endogenous interferon in Argentine hemorrhagic fever. J. Infect. Dis. 149:428-433.

63. Kurane, I., et al. 1993. High levels of interferon alpha in the sera of children with dengue virus infection. Am. J. Trop. Med. Hyg. 48:222-229.

64. McCormick, J.B., and Fisher-Hoch, S.P. 2002. Lassa fever. Curr. Top. Microbiol. Immunol. 262:75-109.

65. Villinger, F., et al. 1999. Markedly elevated levels of interferon (IFN)-gamma, IFN-alpha, interleukin (IL)-2, IL-10, and tumor necrosis factor-alpha associated with fatal Ebola virus infection. J. Infect. Dis. 179(Suppl. 1):S188-S191.

66. Peters, J.H., Gieseler, R., Thiele, B., and Steinbach, F. 1996. Dendritic cells: from ontogenetic orphans to myelomonocytic descendants. Immunol. Today. 17:273-278.

67. Pierre, P., and Mellman, I. 1998. Developmental regulation of invariant chain proteolysis controls $\mathrm{MHC}$ class II trafficking in mouse dendritic cells. Cell. 93:1135-1145

68. Stumptner-Cuvelette, P., et al. 2001. HIV-1 Nef impairs MHC class II antigen presentation and surface expression. Proc. Natl. Acad. Sci. U. S. A. 98:12144-12149.

69. Cebulla, C.M., et al. 2002. Human cytomegalovirus disrupts constitutive MHC class II expression. J. Immunol. 169:167-176. 